\title{
Doses de fósforo e potássio no desenvolvimento da cultura de Crambe abyssinica
}

\section{Phosphorus and potassium doses in the development of Crambe abyssinica culture}

\author{
Ramara Sena de Souza ${ }^{1}$, Lúcia Helena Garófalo Chaves ${ }^{2}$
}

\begin{abstract}
Resumo: A cultura do crambe (Crambe abyssinica) é uma alternativa para produção de biodisel recebendo este enfoque por sua rusticidade, precocidade, alto teor de óleo e adaptabilidade. Os nutrientes minerais possuem funções essenciais e específicas no metabolismo das plantas. A aplicação de fertilizantes minerais é feita para repor sua perda, pois a cada ciclo as plantas extraem nutrientes dos solos. O manejo adequado do uso de fertilizantes no cultivo do crambe é pouco conhecido, não havendo recomendações específicas para a adubação. Portanto, objetivou-se estudar os efeitos da adubação mineral relativa aos elementos fósforo e potássio, no crescimento e na produção do crambe. O experimento foi instalado em casa de vegetação, com delineamento inteiramente casualizado em esquema fatorial 4 x $4+1$, com três repetições, totalizando 51 unidades experimentais. As doses de fósforo e potássio utilizadas foram 50; 75; 100 e $125 \mathrm{~kg} \mathrm{ha}^{-1}$. Aos 60 dias após o semeio (DAS) foram analisadas altura das plantas, diâmetro caulinar e número de ramificações. As plantas foram colhidas em fase de maturação aos 90 DAS, quando foram avaliadas a massa seca total das plantas, número de grãos por planta e massa de mil grãos. O crescimento e a produção do crambe, nestas condições, foram pouco influenciados pela aplicação de fósforo e potássio, provavelmente, porque a cultura foi prejudicada pela falta de adubação nitrogenada.
\end{abstract}

Palavras-chave: Culturas energéticas, adubação mineral, biodisel.

\begin{abstract}
Mineral nutrients have essential and specific roles in plant metabolism. The application of mineral fertilizers is made to replenish its loss, for every cycle of the plant extract soil nutrients. The crambe culture is an alternative for the production of biodiesel getting this approach for its rusticity, precocity, high oil content and adaptability. Proper management of fertilizer use in crambe cultivation is little known and no specific recommendations for fertilizer. Therefore, the objective of this research was to study the effects of mineral fertilizers on the elements phosphorus and potassium on growth and production of crambe. The experiment was installed in a greenhouse, with a completely randomized design in a factorial $4 \mathrm{x} 4$ +1 , with three repetitions, totaling 51 experimental units. Phosphorus and potassium levels the used were 50; 75; 100 and 125 $\mathrm{kg} \mathrm{ha}^{-1}$. The use of these elements caused no significant effect on the growth and production of crambe. Sixty days after sowing (DAS) plant height, stem diameter and number of branches were analyzed. Plants were harvested at maturity stage at 90 DAS, when the total dry weight of plants, number of grains per plant and thousand grain weights were evaluated. The growth and production of crambe, these conditions were little influenced by the application of phosphorus and potassium, probably because culture was hampered by a lack of nitrogen fertilization.
\end{abstract}

Key words: Energy crops, mineral fertilizers, biodiesel.

\footnotetext{
*Autor para correspondência

Recebido para publicação em 11/04/2016; aprovado em 12/06/2016

${ }^{1}$ Doutoranda no Programa de Pós Graduação em Engenharia Agrícola, Universidade Federal de Campina Grande, Campina Grande, ramarasena2005@yahoo.com.br

${ }^{2}$ Professora Titular do DEAg/CTRN, Universidade Federal de Campina Grande, Campina Grande, lhgarofalo@hotmail.com
} 


\section{INTRODUÇÃO}

O crambe (Crambe abyssinica Hoechst), demostra-se atualmente como uma alternativa interessante para a produção de biodiesel por apresentar vantagens como precocidade, rusticidade, boa tolerância às variações climáticas, baixo custo de produção e produtividade entre 1000 e $1500 \mathrm{~kg} \mathrm{ha}^{-1}$, maior produção de óleo em relação às culturas como girassol, nabo forrageiro, canola e pinhão-manso, entre outras. Além disto, o crambe não compete com culturas destinadas à produção de alimento, tornando-se viável o seu cultivo para a produção de biocombustível (JASPER et al., 2010).

Os nutrientes minerais possuem funções essenciais e específicas no metabolismo das plantas; quando algum desses não está presente nas condições satisfatórias à planta, sua deficiência gera anomalias em virtude de alterações no metabolismo. O fósforo, por exemplo, entre várias funções, estimula o desenvolvimento radicular e o florescimento, apressa a maturação fisiológica, ajuda a formação das sementes e aumenta a produtividade (MALAVOLTA, 1989). Da mesma forma, o potássio é um macronutriente importante, principalmente para a síntese de proteínas e de carboidratos, para a produção de fotoassimilados para os grãos, controla a água na planta e para o processo de abertura e fechamento dos estômatos, regula a assimilação de $\mathrm{CO}_{2}$, estimula o crescimento vegetativo, além de atuar no balanço iônico (MARSCHNER, 1995).

A cada ciclo as plantas extraem nutrientes dos solos podendo esgotá-los caso os nutrientes não são repostos aos solos através da aplicação de fertilizantes. Crambe (Crambe abyssinica Hoechst), oleaginosa pertencente à família Brassicaceae, como outras plantas superiores, necessita de macro e micronutrientes e a resposta à fertilidade do solo é semelhante à de pequenos grãos (KNIGHTS, 2002), como a Brassica napus L, Brassica rapa L. e a Brassica juncea L. Pesquisas estão sendo realizadas em relação à nutrição e/ou adubação do crambe, no entanto, ainda não há recomendações específicas para a cultura (ROGÉRIO et al., 2012) e se desconhece sua resposta à adubação (ROSOLEM; STEINER, 2014).

Portanto, em virtude dos fatos mencionados e das possibilidades econômicas, principalmente pelo crambe representar possivelmente, uma nova opção de cultivo para as terras das regiões semiáridas do Nordeste, objetivou-se, estudar os efeitos da utilização da fertilização mineral, referentes aos elementos fósforo e potássio, no crescimento e na produção da cultura do crambe, tendo em vista que os mesmos são considerados macronutrientes essências para o desenvolvimento das plantas.

\section{MATERIAL E MÉTODOS}

O experimento foi realizado em casa de vegetação pertencente à Unidade Acadêmica de Engenharia Agrícola (UAEAg), do Centro de Tecnologia e Recursos Naturais (CTRN) da Universidade Federal de Campina Grande UFCG, em Campina Grande-PB. As coordenadas geográficas do local são $7^{\circ} 13^{\prime} 11^{\prime \prime}$ Sul e $35^{\circ} 53^{\prime} 31^{\prime}$ Oeste e altitude de $550 \mathrm{~m}$.

Como substrato utilizou-se um Neossolo Quartzarênico proveniente do município de Campina Grande-PB, coletado da camada superficial $(0-20 \mathrm{~cm})$ e caracterizado quanto aos aspectos físicos e químicos segundo metodologia descrita pela Embrapa (1997). Os resultados foram os seguintes: $\mathrm{pH}$ $\left(\mathrm{H}_{2} \mathrm{O}\right)=7.1 ; \mathrm{Ca}=1,92 \mathrm{cmol}_{\mathrm{c}} \mathrm{kg}^{-1} ; \mathrm{Mg}=1,44 \mathrm{cmol}_{\mathrm{c}} \mathrm{kg}^{-1} ; \mathrm{Na}$ $=0,16 \mathrm{cmol}_{\mathrm{c}} \mathrm{kg}^{-1} ; \mathrm{K}=0,19 \mathrm{cmol}_{\mathrm{c}} \mathrm{kg}^{-1} ; \mathrm{H}=0,0 \mathrm{cmol}_{\mathrm{c}} \mathrm{kg}^{-1} ; \mathrm{Al}$ $=0,0 \mathrm{cmol}_{\mathrm{c}} \mathrm{kg}^{-1} ; \mathrm{OM}=4,8 \mathrm{~g} \mathrm{~kg}^{-1} ; \mathrm{P}=14,3 \mathrm{mg} \mathrm{dm}{ }^{-3} ;$ areia $=$ $874,0 \mathrm{~g} \mathrm{~kg}^{-1}$; silte $=50,5 \mathrm{~g} \mathrm{~kg}^{-1}$; argila $=75,5 \mathrm{~g} \mathrm{~kg}^{-1}$. De acordo com estes resultados o solo foi classificado como Areia Franca.

O delineamento experimental foi $\mathrm{o}$ inteiramente casualizado (DIC) em esquema fatorial $4 \times 4+1$, com três repetições, totalizando 51 unidades experimentais. Os tratamentos corresponderam a combinação de 4 doses de potássio $\left(50,75,100\right.$ e $\left.125 \mathrm{~kg} \mathrm{ha}^{-1} \mathrm{de}_{2} \mathrm{O}\right)$ com 4 doses de fósforo $\left(50,75,100\right.$ e $\left.125 \mathrm{~kg} \mathrm{ha}^{-1} \mathrm{de}_{2} \mathrm{O}_{5}\right)$, utilizando cloreto de potássio e fosfato super simples, respectivamente.

Cada unidade experimental foi constituída por um vaso de polietileno preenchido com $20 \mathrm{~kg}$ de solo, sobre o qual foram depositados 600 gramas de matéria orgânica a fim de garantir uma germinação uniforme das sementes de crambe. Em cada unidade foram semeadas sete sementes de crambe, cultivar FMS Brilhante, proveniente da Fundação Mato Grosso do Sul, distribuídas de forma equidistante, em uma profundidade de $0,02 \mathrm{~m}$; aos quinze dias após o semeio (DAS) foi realizado o desbaste deixando-se duas plantas por unidade experimental.

As adubações potássica e fosfática foram feitas em fundação, com as dosagens correspondentes aos tratamentos; em seguida o solo foi irrigado até atingir a capacidade de campo de forma a garantir a efetivação do processo de germinação e do desenvolvimento das plântulas. O conteúdo de água no solo foi monitorado através de pesagem das unidades experimentais e a irrigação foi realizada manualmente utilizando-se regadores contendo água proveniente do sistema de abastecimento, mantendo-se capacidade de campo do solo. As variáveis analisadas durante o ciclo de desenvolvimento do crambe foram: altura das plantas, mensurada em metros, com uma trena, medindo-se a distância do colo até o ápice da planta, a cada trinta dias; diâmetro caulinar, medido com paquímetro digital, em milímetros, na parte basal da planta, aos 60 DAS; número de ramificações, determinado aos 60 DAS, contando-se os ramos primários e secundários de cada planta.

As plantas foram colhidas em fase de maturação aos 90 DAS, tempo correspondente ao fim do ciclo da cultura, quando foram avaliadas as seguintes variáveis de produção: massa seca total, determinada por meio de secagem das partes frescas da planta em estufa de circulação de ar forçado a uma temperatura de $60{ }^{\circ} \mathrm{C}$ e posterior pesagem; número de grãos por planta fazendo-se o debulhamento manual e contando-se o número de silíquas de cada planta e massa de mil grãos, determinada através da pesagem de 1000 silíquas.

Os resultados obtidos foram submetidos à análise de variância, através da utilização do software SISVAR-ESAL (FERREIRA, 2000). Por se tratarem de fatores quantitativos utilizou-se o tipo de regressão por polinômios ortogonais.

\section{RESULTADOS E DISCUSSÃO}

De acordo com a análise de variância as doses utilizadas de fósforo não tiveram efeito significativo na altura de plantas, no diâmetro caulinar e no número de ramificações. A aplicação de potássio influenciou significativamente somente na altura de plantas aos 60 DAS e no número de ramificações. A interação do fósforo com o potássio influenciou a altura de 
plantas aos 30 DAS sendo que apenas as combinações de fósforo com a $75 \mathrm{~kg} \mathrm{ha}^{-1}$ e $100 \mathrm{~kg} \mathrm{ha}^{-1}$ de potássio foram significativas representadas pelas equações linear e quadrática, respectivamente (Tabela 1). De acordo com Freitas (2010), a aplicação de fósforo e de potássio na cultura do crambe, não teve efeito significativo na altura de plantas e no número de ramificação.

Mesmo não havendo significância para o número de ramificações, o comportamento dessa variável, conforme o fósforo relacionado com $75 \mathrm{~kg} \mathrm{ha}^{-1}$ de potássio foi relevante quanto à forma linear. E, finalmente, não houve diferença das doses de fósforo e de potássio em relação à testemunha (Tabela1). A média real do número de ramificações foi 31,06, ou seja, maior do que foi observado por Freitas (2010), 11,31.

De modo geral, foi observado neste experimento que, apesar de serem aplicadas doses crescentes de fósforo e potássio na cultura, as plantas desenvolveram-se com baixo vigor vegetativo, alcançando o estado de maturação até vinte dias antes do período normal (em torno de 90 DAS), caracterizando um encurtamento do ciclo. Além disto, foi observado menor número de folhas, coloração amarelada e menor floração, tornando-se as plantas, consequentemente, mais susceptíveis as pragas.
Todos esses efeitos podem ser evidenciados pela falta de nitrogênio no desenvolvimento das plantas, corroborando Colodetti et al. (2013). Estes autores constataram, analisando as plantas de crambe cultivadas sob condições de deficiência de $\mathrm{N}$, encurtamento do seu ciclo fenológico atingindo o estádio de florescimento em curto período de tempo.

Com relação ao vigor vegetativo, Colodetti et al. (2012) ainda demonstraram a necessidade de adubação com N, P e K com níveis acima do recomendado para que as plantas de crambe se desenvolvam com vigor vegetativo elevado. De acordo com Oliveira et al. (1996) quando as plantas são deficientes em relação ao nitrogênio, as mesmas são atrofiadas, o caule e o ramo são delgados e as folhas apresentam coloração entre verde-pálido e amarela.

A adubação nitrogenada, quanto em quantidades adequadas para a planta, estimula o desenvolvimento radicular, garante uma arrancada vigorosa, apressa a maturação fisiológica, estimula a fotossíntese, aumenta a resistência ao frio dos cereais e também aumenta a produtividade (MALAVOLTA, 1989). O nitrogênio pode, ainda, atuar como regulador, exercendo considerável expressão do potássio (K), e fósforo $(\mathrm{P})$ no crescimento vegetal (EPSTEIN, 2004).

Tabela 1. Resumo da análise de variância para a altura da planta (AP), diâmetro caulinar (DC) e número de ramificações (NR) do crambe, em função da utilização dos elementos fósforo $(\mathrm{P})$ e potássio $(\mathrm{K})$

\begin{tabular}{|c|c|c|c|c|c|c|}
\hline \multirow[t]{2}{*}{ Fonte de variação } & \multirow{2}{*}{$\begin{array}{c}\text { Grau de } \\
\text { liberdade }\end{array}$} & \multicolumn{4}{|c|}{ Quadrado médio } & \multirow[b]{2}{*}{ NR } \\
\hline & & AP 30 & AP 60 & AP 90 & DP & \\
\hline Fósforo $(\mathrm{P})$ & 3 & $0,0003^{\mathrm{ns}}$ & $0,01^{\mathrm{ns}}$ & $0,008^{\mathrm{ns}}$ & $1,61^{\mathrm{ns}}$ & $0,00138^{\mathrm{ns}}$ \\
\hline Potássio (K) & 3 & $0,0003^{\mathrm{ns}}$ & $0,06^{*}$ & $0,016^{\mathrm{ns}}$ & $0,59^{\mathrm{ns}}$ & $0,002^{\mathrm{ns}}$ \\
\hline $\mathrm{P} \times \mathrm{K}$ & 9 & $0,00054 *$ & $0,01^{\mathrm{ns}}$ & $0,009^{\mathrm{ns}}$ & $1,05^{\mathrm{ns}}$ & $0,001^{\mathrm{ns}}$ \\
\hline $\mathrm{P}$ dentro de $\mathrm{K} 1$ & 1 & - & - & - & - & - \\
\hline $\mathrm{P}$ dentro de $\mathrm{K} 2$ & 1 & $0,003^{*}(\mathrm{~L})$ & - & - & - & $0,004 *(\mathrm{~L})$ \\
\hline $\mathrm{P}$ dentro de $\mathrm{K} 3$ & 1 & $0,001^{*}(\mathrm{Q})$ & - & - & - & - \\
\hline Test. vs Fator & 1 & $0,001^{\mathrm{ns}}$ & $0,01^{\mathrm{ns}}$ & $0,015^{\mathrm{ns}}$ & $0,59^{\mathrm{ns}}$ & $0,00^{\mathrm{ns}}$ \\
\hline Média geral & & 0,08 & 1,032 & 1,09 & 7,98 & 0,19 \\
\hline $\mathrm{CV}(\%)$ & & 19,28 & 13,45 & 8,66 & 15,08 & 16,02 \\
\hline
\end{tabular}

A aplicação de fósforo e potássio na cultura de crambe não apresentou efeito significativo sobre as variáveis de produção desta cultura (Tabela 2) corroborando com Freitas (2010) que também não encontrou diferença significativa entre os resultados da aplicação de $\mathrm{P}_{2} \mathrm{O}_{5}$ e $\mathrm{K}_{2} \mathrm{O}$ em crambe.

Os valores da massa de mil grãos $(6,74 \mathrm{~g})$ e da massa seca total $(10,43 \mathrm{~g})$ encontrados por este autor foram menores dos apresentados na Tabela 2. Santos et al. (2012), aplicando doses crescentes de potássio em um Latossolo Vermelho distroférrico muito argiloso não encontrou aumentos na produtividade de grãos nas safras de 2008 e 2009, em decorrência do solo apresentar alto nível de disponibilidade de potássio. No entanto, a aplicação de doses de potássio em um Latossolo Vermelho distrófico típico, influenciou positivamente na produtividade da cultura do crambe, porém, não incrementou na massa seca, massa de 100 grãos e no teor de óleo. Rosolem e Steiner (2014) observaram que o teor de $\mathrm{K}$ nos grãos de crambe aumentou com o acréscimo do teor de $\mathrm{K}$ no solo, acompanhando o aumento na produtividade.

Aumentos significativos na produtividade de grãos de canola e de colza, espécies muito semelhantes ao crambe e à adubação potássica, foram relatados na literatura (ÁVILA et al., 2004; BRENNAN; BOLLAND, 2006; BRENNAN;
BOLLAND, 2007a; BRENNAN; BOLLAND, 2007b ; ZOU; LU, 2010) o que não foi verificado nesse experimento para a cultura do crambe.

Rogério et al. (2012) observaram que doses crescentes de fósforo aplicadas em um Latossolo Vermelho distrófico típico, contribuíram para o aumento da produtividade e da massa seca de crambe; da mesma forma, revelaram que o aumento do fósforo resultou na maior produção de grãos e maior produção de óleo por hectare (Rogério et al., 2013) no entanto, não aumentou o teor de óleo das sementes. Conforme Silva et al. (2011), o fósforo aumentou a massa de 1000 grãos, o conteúdo de óleo nas sementes, e consequentemente, a produção do crambe. Embora não tenha observado diferença significativa entre os tratamentos (arranjos nutricionais com base em NPK), o arranjo entre o fósforo e o potássio foi o tratamento que menos contribuiu para o aumento da produtividade matematicamente, seguido pelo tratamento de potássio isolado (LUNELLI, 2012).

Os resultados apresentados evidenciam há não existência de definição a respeito do manejo adequado da adubação do crambe, ou seja, quais nutrientes devem ser fornecidos à planta, quais quantidades e em que épocas adequadas. $\mathrm{O}$ que se sabe, teoricamente, que o crambe não 
apresenta respostas significativas a adubações com NPK no plantio, quando o solo já se encontra corrigido com bons níveis de P e K (PITOL, 2008) e que a maior disponibilidade de $\mathrm{N}$ no solo pode gerar respostas significativas na produção de grãos (BROCH et al., 2010).

Conforme a análise de variância apresentada na Tabela 2 , os resultados do experimento adubado com fósforo e potássio em relação à testemunha, ou seja, sem adubação, mostraram diferenças significativas nos valores correspondentes a massa de mil grãos utilizando as doses 50 $\mathrm{kg} \mathrm{ha}^{-1}$ de $\mathrm{P}_{2} \mathrm{O}_{5}$ com $125 \mathrm{~kg} \mathrm{ha}^{-1} \mathrm{de} \mathrm{K}_{2} \mathrm{O}$. Da mesma forma, houve diferença significativa dos dados de número de grãos por planta e massa de mil grãos utilizando $75 \mathrm{~kg} \mathrm{ha}^{-1}$ de $\mathrm{P}_{2} \mathrm{O}_{5}$ com $50 \mathrm{~kg} \mathrm{ha}^{-1}$ de $\mathrm{K}_{2} \mathrm{O}$. Estas doses de fósforo e potássio tiveram efeito porque os teores no solo, já se apresentavam em um nível alto e médio, respectivamente, tendo como base os valores para soja.

Tabela 2- Análise de variância para o número de grãos por planta (NGP), massa de mil grãos (MMG) e massa seca total (MST) do crambe, em função da utilização dos elementos fósforo (P) e potássio (K)

\begin{tabular}{|c|c|c|c|c|}
\hline \multirow[t]{2}{*}{ Fonte de variação } & \multirow{2}{*}{$\begin{array}{c}\text { Grau de } \\
\text { liberdade }\end{array}$} & \multicolumn{3}{|c|}{ Quadrado médio } \\
\hline & & NGP & MMG & MST \\
\hline Fósforo (P) & 3 & $0,0002^{\mathrm{ns}}$ & $1,61^{\mathrm{ns}}$ & $0,88^{\mathrm{ns}}$ \\
\hline Potássio (K) & 3 & $0,0002^{\mathrm{ns}}$ & $0,74^{\mathrm{ns}}$ & $1,32^{\mathrm{ns}}$ \\
\hline $\mathrm{P} \times \mathrm{K}$ & 9 & $0,0001^{\mathrm{ns}}$ & $2,46^{\mathrm{ns}}$ & $3,03^{\mathrm{ns}}$ \\
\hline Test. vs Fator & 1 & $0,0003 \mathrm{~ns}$ & $10,12^{\mathrm{ns}}$ & $1,38^{\mathrm{ns}}$ \\
\hline Test. $v s \mathrm{P} 1 \mathrm{~K} 4$ & 1 & $0,0003^{\mathrm{ns}}$ & $14,92^{*}$ & $0,006^{\mathrm{ns}}$ \\
\hline Test. $v s \mathrm{P} 2 \mathrm{~K} 1$ & 1 & $0,001^{*}$ & $17,03^{*}$ & $4,08^{\mathrm{ns}}$ \\
\hline Média geral & & 0,08 & $10,64(\mathrm{~g})$ & $13,54(\mathrm{~g})$ \\
\hline $\mathrm{CV}(\%)$ & & 19,09 & 17,76 & 12,28 \\
\hline
\end{tabular}

\section{CONCLUSÕES}

O crescimento e a produção do crambe, nestas condições, foram pouco influenciados pela aplicação de fósforo e potássio, provavelmente, a cultura foi prejudicada pela falta de adubação nitrogenada.

\section{REFERÊNCIAS BIBLIOGRÁFICAS}

ÁVILA, M.R.; BRACCIN, A.L.; SCAPIM, C.A.; ALBRECHT, L.P. Adubação potássica em canola e seu efeito no rendimento e na qualidade fisiológica e sanitária das sementes. Acta Scientiarun Agronomy, v.26, n.4, p.475-481, 2004.

BRENNAN, R.F.; BOLLAND, M.D.A. Soil and tissue tests to predict the potassium requirements of canola in southwestern Australia. Australia. Australian Journal of Experimental Agriculture, v.46, n.5, p.675-679, 2006.

BRENNAN, R.F.; BOLLAND, M.D.A. Comparing the potassium requirements of canola and wheat. Australian Journal of Agricultural Research, v.58, n.4, p.359-366, 2007 a.

BRENNAN, R.F.; BOLLAND, M.D.A. Influence of potassium and nitrogen fertilizer on yield, oil and protein concentration of canola (Brassica napus L.) grain harvested in south-western Australia. Australian Journal of Experimental Agriculture, v.47, n.8, p.976-983, 2007b.

BROCH, D.L.; PITOL, C.; ROSCOE, R. Efeito de adubações de plantio e de cobertura sobre a produtividade de crambe CV. FMS Brilhante após soja e milho. In: Congresso Brasileiro de Mamona, $4^{\circ}$ Simpósio Internacional de Oleaginosas Energéticas, 1, 2010, João Pessoa. Inclusão Social e Energia: Anais Campina grande: Embrapa Algodão, 2010. p. 1339-1344.
COLODETTI, T.V.; CHRISTO, L.F.; TOMAZ, M.A.; AMARAL, J.F.T.; MARTINS, L.D.; RODRIGUES, W. N. Vigor vegetativo de crambe em função de níveis de N, P e K. In: Congresso da Rede Brasileira de Tecnologia de Biodiesel, 5., Congresso Brasileiro de Plantas Oleaginosas, Óleos, Gorduras e Biodiesel, 8; 2012; Salvador. Lavras: UFLA, 2012. (CD-ROM).

COLODETTI, T.V., RODRIGUES, W.N.; CHRISTO, L.F.; MARTINS, L.D.; TOMAZ, M.A. Perda de biomassa causada pela deficiência de macronutrientes em Crambe abyssinica. Enciclopédia biosfera, Goiânia, v.9, n.17, p. 2027-2038, 2013.

EMBRAPA - Empresa Brasileira de Pesquisa Agropecuária. Centro Nacional de Pesquisa de Solo. Manual de métodos de análise de solo. 2 ed. Rio de Janeiro: EMBRAPA. Serviço Nacional de Levantamento e Conservação de Solo, 1997. 212 p.

EPSTEIN, E.; BLOOM, A.J. Nutrição mineral de plantas: princípios e perspectivas. 2. ed. Londrina:Planta; 2004. 403 p.

FERREIRA, D.F. Sistema de análises de variância para dados balanceados. Lavras: UFLA (SISVAR 4. 1. Pacote computacional), 2000. 169 p.

FREITAS, M. E. Comportamento Agronômico da cultura do Crambe (Crambe abyssinica Hochst) em função do manejo empregado. 2010. 42f. Dissertação. Dourados (MS): Universidade Federal da Grande Dourados, Dourados. 2010.

JASPER, P.A.; BIAGGIONI, M.A.M.; SILVA, P.R.A.; SEKI, A.S.; BUENO, C.O. Análise Energética da Cultura do Crambe (Crambe abyssinica Hochst) produzida em Plantio Direto. Engenharia Agrícola, Jaboticabal, v.30, n.3, p.395403, 2010. 
KNIGHTS, S.E. Crambe: A North Dakota Case Study. A report for the Rural Industries Research and Development Corporation, 2002. 25 p.

LUNELLI, I.E. Efeitos de arranjos nutricionais de NPK na produtividade de grãos e rendimento de óleo da cultura do crambe. 2012.40f. Dissertação. Universidade Estadual do Oeste do Paraná, Cascavel. 2012.

MALAVOLTA, E. Abc da adubação. São Paulo: Agronômica Ceres, 1989. 304 p.

MARSCHNER, H. Mineral nutrition of higher plants.2.ed. London: Academic Press, 1995. 889 p.

OLIVEIRA, I.P.; ARAÚJO, R.S.; DUTRA, L.G. Nutrição mineral e fixação biológica de nitrogênio. In: ARAUJO, R.S.; RAVA, C.A.; STONE, L.F.; ZIMMERMANN, M.J.O. Cultura do feijoeiro comum no Brasil. Piracicaba: Potafós, 1996. 184 p.

PITOL, C. Cultura do crambe. In: Tecnologia de produção: Milho safrinha e culturas de inverno. Maracajú: Fundação MS, 2008. p. 85-88.

ROGÉRIO, F.; SANTOS, J.I.; SILVA, T.R.B.; MIGLIAVACCA, R.A.; GOUVEIA, B.; BARBOSA, M.C Efeito de doses de fósforo no desenvolvimento da cultura do crambe. Bioscience Journal, Uberlandia, v. 28, (Sup. 1), p. 251-255, 2012.
ROGÉRIO, F.; SILVA, T.R.B.; SANTOS, J.I.; POLETINE, J.P. Phosphorus fertilization influences grain yield and oil content in crambe. Industrial Crops and Products, v.41, p.266- 268, 2013.

ROSOLEM, C.A.; STEINER, F. Adubação potássica para o crambe. Bioscience Journal, Uberlandia, v.30, (Sup. 1), p. 140-146, 2014.

SANTOS, J.I.; ROGÉRIO, F.; MIGLIAVACCA, R.A.; GOUVEIA, B.; SILVA, T.R.B.; BARBOSA, M.C. Efeito da adubação potássica na cultura do crambe. Bioscience Journal, Uberlandia, v.28, n.3, p.346-350, 2012.

SILVA, T.R.B.; LAVAGNOLLI, R.F.; NOLLA, A. Zinc and phosphorus fertilization of crambe (Crambe abysinica Hoechst). Journal of Food Agriculture \& Environment, Finlandia, v.9, n.1, p.264-267, 2011.

ZOU, J.; LU, J.W. Yield response of winter rapeseed to potassium fertilization, use efficiency and soil's potassium critical level in the Yangtze River Valley. e-ifc - International Fertilizer Correspondent. n. 23, 2010. p.13-20. Disponível em http://www.ipipotash.org/eifc/2010/23/4. 